\title{
Patterns of mental health care in a seaside lodging house
}

\author{
JOHN BARNES, Honorary Senior Registrar, The London Hospital Medical College \\ Academic Department of Psychiatry, Runwell and Basildon Hospitals, \\ Runwell Hospital, Wickford, Essex SS11 7QE; and GREG WILKINSON, Professor, \\ The London Hospital Medical College Academic Department of Psychiatry, \\ London E1 2AD
}

Much of the medical care of the long-term mentally ill falls to the general practitioner (Wilkinson et al, 1985) and, for example, a survey in Buckinghamshire showed that these patients consult their general practitioner (GP) twice as often as mental health services. Lodging house dwellers are known to show an increased prevalence of major mental illness and to suffer much secondary social handicap, presenting a challenge to helping services of all disciplines. For this reason we chose a lodging house in which to explore further the relationships between mental illness and residents' present contact with their GP, mental health services and other local sources of help.

\section{The study}

This small study was carried out in a 30 bedded lodging house in Southend, which accepts people discharged by local psychiatric units and is visited regularly by a community psychiatric nurse. The aims were to compare residents who were expsychiatric patients, with the residents currently using psychiatric services, with regard to personal history and illness factors, and the pattern of support residents received from statutory, voluntary and informal sources. Also, the remaining residents, i.e. those who denied any contact with psychiatric services, were compared to the "ex-patient" and "current patient" groups with respect to the above sources of support. All residents were invited to be interviewed for 90 minutes, clinical data were recorded on a prepared schedule, and ratings were made using the BPRS (Overall \& Gorham, 1962) (in all residents) and the Positive and Negative Syndrome Scale (PANSS) (in those with schizophrenia) (Kay et al, 1987). Primary diagnoses in patients were obtained from the hospital case-notes.

\section{Findings}

Five of the 30 residents declined to participate. This may be a source of bias since one of the refusers was observed to have marked thought disorder.

\section{Socio-demographic characteristics}

The sample consisted of $18(72 \%)$ males and $7(28 \%)$ females. Their ages ranged from 28-89 years (mean 55 years). Seventeen $(68 \%)$ were unemployed, only two $(8 \%)$ were employed, and six $(24 \%)$ were retired. Five $(20 \%)$ residents were married, but four of them were separated from their spouses. Eleven (44\%) were single, seven $(28 \%)$ were divorced and two (8\%) were widowed.

\section{Category of resident by service use}

Three categories of resident were identified based on their use of psychiatric services; seven were currently in contact with services, ten were ex-psychiatric patients who were no longer in contact with services: and eight residents who reported that they had never used psychiatric services.

\section{Social dificulties}

The sample as a whole had a high prevalence of social difficulties. In the previous 12 months, $14(56 \%)$ had not seen any relation and $16(64 \%)$ had not seen a close friend. At one time or another $13(52 \%)$ had slept rough due to lack of accommodation. Eight $(32 \%)$ residents had criminal convictions and four of them had served a custodial sentence.

\section{Psychiatric diagnosis and history}

Considering the case-notes diagnosis of those 17 residents who had had previous contact with psychiatric services, $7(41 \%)$ had schizophrenia, $3(18 \%)$ had manic-depressive illness, $2(12 \%)$ had depressive illness, $2(12 \%)$ had neuroses, $1(6 \%)$ had brain damage after head injury, $1(6 \%)$ had personality disorder, and $1(6 \%)$ had alcohol dependence. Sixteen $(94 \%)$ had been psychiatric in-patients and eight of them had been admitted under the Mental Health Act. Four (23\%) had stayed in hospital for between one and five years and three $(18 \%)$ patients had stayed for five years or more. 


\section{Diagnosis in ex-psychiatric patients now under GP} care

The ten ex-psychiatric patients now under GP care thus exhibited a far wider range of morbidity than the current psychiatric patients, including a functional and organic psychosis, depressive illness, personality disorder, neuroses and alcohol dependency. The seven patients with continuing contact with psychiatric services all had a diagnosis of a psychotic illness, five had schizophrenia and two had manic-depressive illness.

\section{Patients' severity of psychopathology, GP care v. specialist care}

The presence of more acute psychotic symptoms seemed to act as a 'passport' to specialist services. Residents with schizophrenia, solely under GP care had lower mean PANSS scores for positive symptoms of schizophrenia (8), than their counterparts currently in contact with psychiatric services (17). However, negative symptoms were more evenly distributed (Spearmans coefficient of correlation with psychiatric service contact: positive symptoms 0.74 ; negative symptoms 0.36 ). The mean BPRS scores were lower in the ex-patients (26) than the current psychiatric patients (37), although this narrowly failed to meet statistical significance $(U=15.5$, $P=$.056).

\section{Residents' use of GPs compared to other sources of support}

Residents as a whole had more frequent contact with GPs than psychiatric or social services. GP contact tended to be greater in those who had lost contact with psychiatric services than in other residents. Of the ex-psychiatric patients, seven $(70 \%)$ were seeing their GP monthly, compared to three (43\%) of the current psychiatric patients and three $(60 \%)$ of the controls. Seeing a relative or visiting a public house were the next most frequent contact in the previous six months, occurring in nine $(36 \%)$ residents. Close friends had been seen by eight $(32 \%)$ residents. The least frequent contacts occurring in the previous six months were with a social worker, a church or club and a library, all occurring in less than $20 \%$ of residents. In those residents still in contact with psychiatric services, the community psychiatric nurses were the most frequent contact, occurring monthly in four $(57 \%)$.

\section{Comment}

The key support to residents with the full range of psychiatric diagnoses were the local GPs. These included residents with conditions which psychiatric services traditionally find difficult to manage, such as personality disorder, and with symptoms largely resistant to drug treatment, such as residual negative symptoms of schizophrenia. Although some of the "GP only" patients suffered from more "minor" conditions than the major psychoses, such as neurotic illnesses, their illnesses were just as severe in terms of history of psychiatric admission, and they had just as many current social difficulties. Conversely, the psychiatric services offered a 'psychosis only' service to the hotel residents, having contact with those residents with the highest levels of acute psychotic symptoms.

If the Government's new objectives to reduce psychiatric and social morbidity (Department of Health, 1992) are to be met, liaison schemes between psychiatrists and general practitioners should be encouraged. These schemes can provide GPs with better support in the management of their patients with severe chronic psychiatric problems, who are not currently in contact with specialist psychiatric services.

\section{Acknowledgements}

The authors are grateful to Invicta Pharmaceuticals and The Janssen Research Foundation for their support.

\section{References}

Department OF HEALTH (1992) The Health of the Nation: A Strategy for Health in England. HMSO.

KAY, S. R., Fiszbein, A. \& Opler, L. A. (1987) The Positive and Negative Syndrome Scale for Schizophrenia. Schizophrenia Bulletin, 13, 261-276.

Overall, J. E. \& Gorham, D. R. (1962) The Brief Psychiatric Rating Scale. Psychological Reports, 10, 799-812.

Wilkinson, G., Falloon, I. \& Sen, B. (1985) Chronic mental disorders in general practice. British Medical Journal, 291, 1302-1304. 